\title{
0186 IMPROVING THE DEVELOPMENT OF AN EFFECTIVE BEACH SAFETY INTERVENTION THROUGH AN OBSERVATIONAL STUDY OF RISKY BEACH BEHAVIOUR
}

A Williamson,* J Hatfield, S Sherker, R Brander, A Hayen Correspondence: Department of Aviation, University of New South Wales - UNSW, Sydney, Australia

\subsection{6/ip.2010.029215.186}

Beach safety is determined largely by the choices people make about where they will swim: it is safest to swim in areas that are patrolled by lifeguards or lifesavers, and swimming outside these areas is risky. Our previous research demonstrated that while most NSW beachgoers are aware of this, a significant proportion report swimming outside patrolled areas. This study examined the reasons for beachgoers choosing to swim in safe or risky areas on beaches in the Sydney region. Beachgoers observed swimming in a patrolled area, an unpatrolled area with no rip current, or an unpatrolled area near a rip current were approached and invited to answer questions about their choice to swim in that area of the beach. Over 1000 people were interviewed over two weekends in summer, 2009. The results of the interviews showed that swimming choice was directed primarily by convenience; beachgoers chose the closest area to swim, even though they were aware that the 


\section{IP Safety 2010 abstracts}

patrolled area was safer. Swimmers observed swimming in risky locations showed the least knowledge of rips. Swimmers in risky locations were also more likely to be younger, to not live near the beach and swim regularly and to be less aware of other beach hazards. The study indicates that a specific intervention would be worthwhile for beachgoers who swim outside patrolled areas and further, the study defines who should be targeted to be most effective. 